\title{
ARMAZENAMENTO DE SEMENTES DE CAMU-CAMU (Myrciaria dubia) COM DIFERENTES GRAUS DE UMIDADE E TEMPERATURAS ${ }^{1}$
}

\author{
SIDNEY ALBERTO DO NASCIMENTO FERREIRA² \& DANIEL FELIPE DE OLIVEIRA GENTIL ${ }^{3}$
}

\begin{abstract}
RESUMO - O objetivo do presente trabalho foi avaliar a qualidade fisiológica das sementes de camu-camu (Myrciaria dubia (H.B.K.) McVaugh), com diferentes graus de umidade $\left(46\right.$ e $40 \%$ ), submetidas a diferentes condições (temperatura ambiente - média de $26,5^{\circ} \mathrm{C}$, câmara a $20^{\circ} \mathrm{C}$ e câmara a $10^{\circ} \mathrm{C}$ ) e períodos de armazenamento (30,60, 90, 120 e 150 dias). Após cada período, foram retiradas amostras dos tratamentos para as avaliações do grau de umidade e da qualidade fisiológica das sementes. A redução do grau de umidade afetou negativamente a viabilidade e o vigor das sementes, e a temperatura de $10^{\circ} \mathrm{C}$ não foi favorável ao armazenamento das sementes. Assim, as sementes de camu-camu devem ser armazenadas com grau de umidade elevado (próximo a 46\%) e, preferencialmente, sob temperatura de $20^{\circ} \mathrm{C}$, para manter a viabilidade e o vigor por maior período de tempo.
\end{abstract}

Termos para indexação: conservação de semente, recalcitrante, viabilidade e vigor de semente.

\section{STORAGE OF CAMU-CAMU (Myrciaria dubia) SEEDS WITH DIFFERENT MOISTURE CONTENTS AND TEMPERATURES}

\begin{abstract}
The objective of the present study was to evaluate the physiological potential of camu-camu (Myrciaria dubia (H.B.K.) McVaugh) seeds with different moisture contents $\left(46\right.$ and $40 \%$ ) under different storage conditions (laboratory environment - mean $26,5^{\circ} \mathrm{C}$, cold storage at $20^{\circ} \mathrm{C}$ and $\left.10^{\circ} \mathrm{C}\right)$ and periods $(30,60,90,120$ and 150 days of storage). After each storage period, samples of the treatments were removed to evaluate moisture content and physiological quality of seeds. The reduction of moisture content negatively affected the viability and vigor of seeds and the temperature of $10^{\circ} \mathrm{C}$ was unfavorable for the storage of seeds. Camu-camu seeds should be stored with high moisture content (close of $46 \%$ ) and, preferentially, at a temperature of $20^{\circ} \mathrm{C}$ to maintain viability and vigor for larger period of time.
\end{abstract}

Index terms: seed conservation, recalcitrant, seed viability and vigour.

\section{INTRODUÇÃO}

O camu-camu (Myrciaria dubia (H.B.K.) McVaugh Myrtaceae), também conhecido como caçari e araçá-d'água, é uma espécie frutífera que ocorre espontaneamente nas margens de rios e lagos de água escura da Amazônia, entre as regiões oriental do Peru e central do Estado do Pará, no Brasil. Seus frutos apresentam elevado conteúdo de ácido ascórbico, entre 1.420 e 2.994 mg/100 g de polpa (Roca, 1965; Silva $\&$ Andrade, 1997), sendo superior ao encontrado na maioria das frutas.

A propagação do camu-camu, embora possa ser conduzida com a utilização de métodos assexuados (Enciso \& Villachica, 1993; Ferreira \& Gentil, 1997), é realizada basicamente por via sexuada. O período de semeadura, todavia, está restrito a poucos dias ou a alguns meses após a colheita dos frutos, em decorrência da pequena longevidade das sementes.

A sensibilidade à dessecação constitui um dos fatores relacionados à conservação das sementes de camu-camu, que perdem a viabilidade com a redução do grau de umidade a valores iguais ou inferiores a $19 \%$, sendo este um importante indicativo do comportamento recalcitrante (Gentil \& Ferreira, 2000). Por isso, durante o armazenamento, tem sido sugerida a manutenção do grau de umidade em níveis elevados, através da imersão em água substituída a cada três dias, que pode preservar o desempenho fisiológico das sementes por algumas semanas (Enciso \& Villachica, 1993).

Embora a secagem de sementes recalcitrantes resulte no declínio da viabilidade (Roberts, 1973), a literatura tem reportado, entre as espécies, considerável variação na sensibilidade à dessecação. Farrant et al. (1988), admitindo esta variação, propuseram a separação das sementes recalcitrantes nas categorias altamente recalcitrantes (pequena tolerância à dessecação), moderadamente recalcitrantes (moderada tolerância à dessecação) e minimamente recalcitrantes (elevada tolerância à perda de água). A secagem parcial pode contribuir para a conservação de sementes recalcitrantes (Chin, 1988), mesmo das que toleram dessecação a valores ligeiramente inferiores ao do grau de umidade original.

$\mathrm{Na}$ secagem de sementes recalcitrantes, devem ser considerados o grau de umidade de segurança, o grau de umidade crítico e o grau de umidade letal para cada espécie. O grau de umidade de segurança corresponde à umidade que pode ser atingida com a secagem, sem prejuízos à viabilidade das sementes (Hong \& Ellis, 1992). O grau de umidade crítico refere-se ao grau de umidade no qual é detectado o início da perda de viabilidade (Andrade \& Cunha, 1996). O grau de umidade letal significa o limite a partir do qual todas as sementes perdem a viabilidade (Hong \& Ellis, 1992). No caso das sementes de camu-camu, Gentil \& Ferreira (2000) verificaram que o grau de umidade crítico pode estar situado entre 46 e $37 \%$ e o grau de umidade letal em torno de $19 \%$.

As sementes recalcitrantes apresentam, ainda, sensibilidade a baixas temperaturas de armazenamento, muito embora a temperatura mínima tolerada possa variar entre as espécies (Chin, 1988). Conforme Farrant et al. (1988), as sementes altamente e moderadamente recalcitrantes são sensíveis a baixas temperaturas, enquanto as minimamente recalcitrantes apresentam maior tolerância, desde de que a temperatura seja superior a $0^{\circ} \mathrm{C}$. A redução da temperatura, associada à secagem parcial, pode evitar a germinação das sementes e a proliferação de microrganismos no armazenamento (King \& Roberts, 1979).

Assim, visando contribuir para o estabelecimento de métodos de conservação de sementes de camu-camu, o presente trabalho foi realizado com o objetivo de avaliar a qualidade fisiológica das sementes dessa espécie, com diferentes graus de umidade, submetidas a diferentes condições e períodos de armazenamento.

\section{MATERIALE MÉTODOS}

O experimento foi conduzido nas dependências da Coordenação de Pesquisas em Ciências Agronômicas (CPCA), do Instituto Nacional de Pesquisas da Amazônia (INPA), em Manaus, Amazonas ( $03^{\circ} 08^{\prime}$ $\left.\mathrm{S} ; 60^{\circ} 02^{\prime} \mathrm{W}\right)$.

Os frutos, em ponto de "colheita comercial", ou seja, com a casca apresentando entre 25 e 100\% de coloração púrpura ou vermelha, foram colhidos em plantio (243 indivíduos) estabelecido em ecossistema de terra firme (Estação Experimental de Fruticultura Tropical do INPA) e mantidos em condições de ambiente natural por oito dias, quando então foi realizada a extração manual das sementes. Em seguida, as mesmas foram lavadas em água corrente, tratadas com solução fungicida (Cuprosan a 0,1\%) e colocadas sobre peneiras, visando eliminar a umi-

\footnotetext{
(Trabalho 054/2003). Recebido: 05/02/2003. Aceito para publicação: 11/09/2003.

Dr., INPA - CPCA, Caixa Postal 478, 69011-970, Manaus - AM, e-mail: sanf@inpa.gov.br .

M. Sc., INPA - COAD, E-mail: gentil@inpa.gov.br .
} 
dade superficial excessiva. Posteriormente, as sementes foram acondicionadas em saco plástico duplo e mantidas em ambiente com temperatura média de $26,5^{\circ} \mathrm{C}$, por 16 dias.

Passado esse período, as sementes foram divididas em dois lotes, sendo um destinado ao armazenamento imediato (46\% de umidade) e o outro à secagem, em ambiente com médias de temperatura de $26,5^{\circ} \mathrm{C}$ e de umidade relativa do ar de $85 \%$, por cinco dias, a fim de ser obtido o grau de umidade de $40 \%$. Em seguida, os mesmos foram divididos em amostras de aproximadamente 200 sementes, que foram acondicionadas em saco plástico duplo, sendo lacrado sem deixar espaço vazio entre a massa de sementes e a borda da embalagem. Posteriormente, amostras de cada grau de umidade (lote) foram armazenadas sob diferentes condições: temperatura ambiente (média de $26,5^{\circ} \mathrm{C}$ ), câmara a $20^{\circ} \mathrm{C}$ e câmara a $10^{\circ} \mathrm{C}$. Antes de serem submetidas ao armazenamento, a viabilidade das sementes era de $91 \%$.

Aos 30, 60, 90, 120 e 150 dias de armazenamento foram retiradas amostras dos tratamentos graus de umidade de cada condição de armazenamento para as avaliações do grau de umidade das sementes (4 repetições de 25 sementes) e da emergência de plântulas (4 repetições de 25 sementes). A determinação do grau de umidade foi realizada pelo método de estufa a $105+3^{\circ} \mathrm{C}$ por 24 horas, sendo os resultados expressos na base úmida (Brasil, 1992). A semeadura foi conduzida em caixas de madeira, utilizando o substrato serragem parcialmente decomposta, peneirada e úmida, alocadas em viveiro com $50 \%$ de luminosidade e temperatura não controlada. A irrigação foi feita sempre que necessária, de modo a manter o substrato umedecido.

A emergência das plântulas foi observada diariamente, a partir do aparecimento da parte aérea acima do nível do substrato, que teve início aos 19 dias da semeadura. Aos dois meses e meio da semeadura, foi encerrado o teste de emergência de cada período de armazenamento, quando foram avaliados a altura, o diâmetro do colo, o número de folhas e a massa seca de 10 plântulas, por repetição, escolhidas ao acaso. A massa seca foi determinada após a secagem das plântulas em estufa a $75^{\circ} \mathrm{C}$, por 48 horas. A partir dos dados de emergência foram calculados o índice de velocidade de emergência - IVE (Maguire, 1962) e o tempo médio de emergência - TME (Edwards, 1934).

O delineamento adotado foi o inteiramente casualizado, em esquema fatorial $2 \times 3 \times 5$ (dois graus de umidade, três condições de armazenamento e cinco períodos de armazenamento), com quatro repetições. Na análise estatística, as dados de emergência foram transformados em arco seno raiz quadrada de $\mathrm{x} / 100$ e os de número de folhas em raiz quadrada de $(x+0,5)$. A comparação das médias foi realizada pelo teste de Tukey, ao nível de 5\% de probabilidade.

\section{RESULTADOS E DISCUSSÃO}

Durante o armazenamento das sementes de camu-camu, os graus de umidade (Tabela 1) se mantiveram próximos aos teores iniciais. Desse modo, a embalagem utilizada demonstrou eficiência na manutenção da identidade dos graus de umidade das sementes, independentemente do ambiente de armazenamento.

As médias das variáveis-resposta apresentaram, em geral, diferenças estatísticas significativas para os efeitos isolados de grau de umidade, ambiente e período de armazenamento (Tabela 2), e as médias de IVE e TME para a interação entre grau de umidade e período de armazenamento (Tabela 3).

TABELA 1 - Médias de grau de umidade (\%) de sementes de camu-camu (Myrciaria dubia), armazenadas com diferentes graus de umidade, em diferentes ambientes e períodos de armazenamento.

\begin{tabular}{|c|c|c|c|c|c|c|}
\hline \multicolumn{2}{|c|}{ Tratamento } & \multicolumn{5}{|c|}{ Período de armazenamento (dias) } \\
\hline Grau de umidade & $\begin{array}{c}\text { Ambiente de } \\
\text { armazenamento }\end{array}$ & 30 & 60 & 90 & 120 & 150 \\
\hline $46 \%$ & $\begin{array}{c}\text { Temperatura ambien } \\
\left(26,5^{\circ} \mathrm{C}\right) \\
20^{\circ} \mathrm{C} \\
10^{\circ} \mathrm{C} \\
\end{array}$ & $\begin{array}{l}45,4 \\
43,8 \\
44,4 \\
\end{array}$ & $\begin{array}{l}43,7 \\
45,0 \\
44,2 \\
\end{array}$ & $\begin{array}{l}44,6 \\
43,4 \\
45,2 \\
\end{array}$ & $\begin{array}{l}45,8 \\
44,1 \\
45,4 \\
\end{array}$ & $\begin{array}{l}44,3 \\
43,5 \\
44,6 \\
\end{array}$ \\
\hline $40 \%$ & $\begin{array}{c}\text { Temperatura ambien } \\
\left(26,5^{\circ} \mathrm{C}\right) \\
20^{\circ} \mathrm{C} \\
10^{\circ} \mathrm{C}\end{array}$ & $\begin{array}{l}41,4 \\
39,3 \\
38,8\end{array}$ & $\begin{array}{l}41,3 \\
39,4 \\
41,0\end{array}$ & $\begin{array}{l}40,4 \\
39,3 \\
41,8\end{array}$ & $\begin{array}{l}38,0 \\
38,3 \\
39,1\end{array}$ & $\begin{array}{l}40,4 \\
39,1 \\
40,9\end{array}$ \\
\hline
\end{tabular}

TABELA 2 - Médias das variáveis de viabilidade e de vigor de sementes de camu-camu (Myrciaria dubia), em relação aos fatores grau de umidade, ambiente e período de armazenamento. ${ }^{1}$

\begin{tabular}{|c|c|c|c|c|c|c|c|}
\hline Tratamento & $\begin{array}{c}\text { Emergência } \\
(\%)\end{array}$ & $\mathrm{IVE}^{2}$ & $\begin{array}{l}\mathrm{TME}^{3} \\
\text { (dias) }\end{array}$ & Altura $(\mathrm{cm})$ & $\begin{array}{l}\text { Diâmetro colo } \\
(\mathrm{mm})\end{array}$ & $\begin{array}{l}\text { Número de } \\
\text { folhas }\end{array}$ & Massa seca (g) \\
\hline \multicolumn{8}{|l|}{ Grau de umidade } \\
\hline $46 \%$ & $90 \mathrm{a}$ & $2,86 \mathrm{a}$ & $31 \mathrm{~b}$ & 6,9 a & $1,21 \mathrm{a}$ & $11,0 \mathrm{a}$ & 0,101 a \\
\hline $40 \%$ & $83 \mathrm{~b}$ & $2,29 \mathrm{~b}$ & $37 \mathrm{a}$ & $6,4 \mathrm{~b}$ & $1,11 \quad b$ & $10,1 \mathrm{~b}$ & $0,082 \quad b$ \\
\hline \multicolumn{8}{|c|}{ Ambiente de armazenamento } \\
\hline \multicolumn{8}{|c|}{ Temperatura ambiente } \\
\hline$\left(26,5^{\circ} \mathrm{C}\right)$ & $88 \mathrm{ab}$ & 2,84 a & $31 \mathrm{~b}$ & 7,0 a & 1,22 a & 11,2 a & 0,103 a \\
\hline $20^{\circ} \mathrm{C}$ & 89 a & $2,77 \mathrm{a}$ & $32 \mathrm{~b}$ & 7,1 a & 1,19 a & 11,0 a & 0,103 a \\
\hline $10^{\circ} \mathrm{C}$ & $84 \mathrm{~b}$ & $2,12 \mathrm{~b}$ & $39 \mathrm{a}$ & $6,0 \mathrm{~b}$ & $1,07 \mathrm{~b}$ & $9,5 \mathrm{~b}$ & $0,069 \mathrm{~b}$ \\
\hline \multicolumn{8}{|c|}{ Período de armazenamento } \\
\hline 30 dias & $87 \mathrm{a}$ & $2,31 \mathrm{c}$ & $38 \mathrm{a}$ & 6,7 a & 1,24 a & $10,0 \mathrm{~b}$ & $0,077 \mathrm{c}$ \\
\hline 60 dias & 89 a & $2,58 \mathrm{~b}$ & $34 \mathrm{~b}$ & $6,5 \mathrm{a}$ & $1,18 \mathrm{ab}$ & $10,4 \mathrm{ab}$ & $0,083 \mathrm{bc}$ \\
\hline 90 dias & 87 a & $2,63 \mathrm{~b}$ & $33 \mathrm{c}$ & 6,6 a & $1,13 \mathrm{~b}$ & $10,4 a b$ & 0,087 bc \\
\hline 120 dias & $83 \mathrm{a}$ & $2,47 \mathrm{bc}$ & $34 \mathrm{bc}$ & 6,6 a & $1,12 \quad b$ & $10,7 \mathrm{ab}$ & $0,094 \mathrm{~b}$ \\
\hline 150 dias & 88 a & 2,89 a & $31 \mathrm{~d}$ & 6,9 a & $1,14 \mathrm{~b}$ & $11,3 \mathrm{a}$ & 0,115 a \\
\hline C.V. $(\%)$ & 12,2 & 12,6 & 2,4 & 10,6 & 10,9 & 5,8 & 18,9 \\
\hline
\end{tabular}

1 - Médias seguidas da mesma letra nas colunas, dentro de cada fator, não diferem significativamente entre si pelo teste de Tukey, ao nível de 5\% de probabilidade. 2 - Índice de velocidade de emergência.

3 - Tempo médio de emergência. 
TABELA 3 - Médias do índice de velocidade de emergência (IVE) e do tempo médio de emergência (TME) para o fator período de armazenamento dentro de cada nível do fator grau de umidade de sementes de camu-camu (Myrciaria dubia). ${ }^{1}$

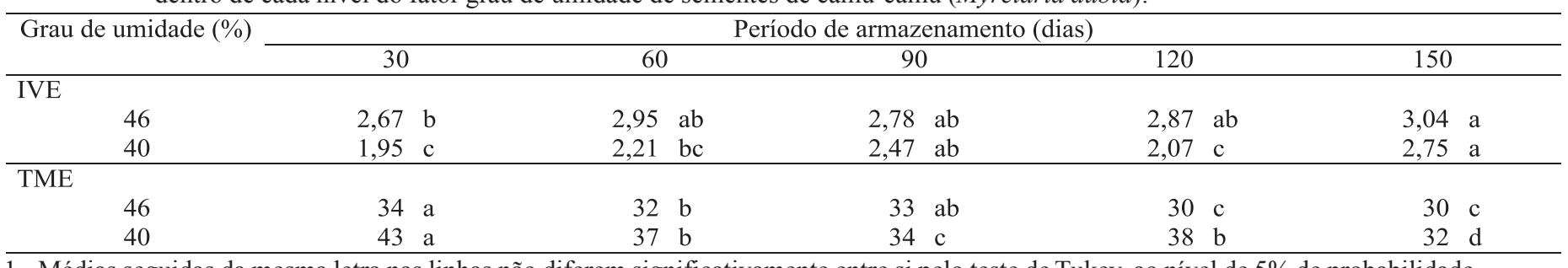

1 - Médias seguidas da mesma letra nas linhas não diferem significativamente entre si pelo teste de Tukey, ao nível de 5\% de probabilidade.

A redução do grau de umidade, de $46 \%$ para $40 \%$, afetou negativamente a viabilidade e o vigor das sementes armazenadas (Tabela 2 ). Com isso, ocorreu a redução da porcentagem e da velocidade de emergência, da altura, do diâmetro do colo, do número de folhas e da massa seca das plântulas, além do aumento do tempo médio de emergência das plântulas. Em trabalho paralelo, realizado com sementes da mesma procedência (data e local) que as utilizadas no presente estudo, Gentil \& Ferreira (2000) também verificaram os efeitos prejudiciais do decréscimo do grau de umidade, de $46 \%$ para $37 \%$, sobre a qualidade fisiológica das sementes, sugerindo que o grau de umidade crítico estivesse situado entre esses valores. Entretanto, considerando que foram observados danos provocados pela dessecação às sementes com $40 \%$ de umidade, é mais provável que o grau de umidade de segurança e o grau de umidade crítico estejam localizados entre 46 e $40 \%$ de umidade.

No que se refere ao fator ambiente de armazenamento, tanto para a emergência quanto para o vigor das sementes (Tabela 2), a temperatura de $10^{\circ} \mathrm{C}$ apresentou, na maior parte das variáveis avaliadas, resultados significativamente inferiores em relação as demais condições. Isso pode indicar o efeito deletério provocado por baixa temperatura às sementes de camu-camu, o que é comumente constatado em sementes recalcitrantes (Chin, 1988). Por outro lado, estes resultados se opõem à recomendação de Enciso \& Villachica (1993), que indicaram a temperatura de $5^{\circ} \mathrm{C}$ para o armazenamento de sementes de camu-camu. Entre a temperatura ambiente (média de $26,5^{\circ} \mathrm{C}$ ) e a câmara a $20^{\circ} \mathrm{C}$, não foram observadas diferenças significativas entre as médias das variáveis; todavia, deve-se dar preferência à temperatura de $20^{\circ} \mathrm{C}$ quando for armazenar as sementes, pois as temperaturas "subambiente" concorrem para a redução da velocidade da deterioração e, com isso, podem aumentar o período de conservação.

Quanto ao fator período de armazenamento, a emergência das plântulas não foi afetada significativamente, tendo a viabilidade permanecida elevada pelo período de cinco meses (Tabela 2). Por outro lado, as variáveis de vigor comportaram-se de maneiras distintas com o aumento do período de armazenamento (Tabela 2): o IVE, o número de folhas e a massa seca tenderam a aumentar; o TME e o diâmetro do colo diminuíram; e a altura das plântulas manteve-se inalterada.

Através do comportamento das variáveis índice de velocidade de emergência (IVE) e tempo médio de emergência (TME) (Tabela 2), evidenciou-se a ocorrência de dormência nas sementes de camu-camu e que a mesma foi sendo reduzida no decorrer do armazenamento. Por conseguinte, as plântulas que emergiram mais rápido fotossintetizaram mais cedo, emitiram mais folhas e acumularam mais matéria seca. Comportamento similar a esse foi observado em outras espécies que apresentam sementes recalcitrantes, quando armazenadas com graus de umidade elevados por curto período de tempo (Farrant et al., 1989). Segundo Farrant et al. (1989), o armazenamento nessas condições resultou na iniciação de eventos metabólicos típicos da germinação, como o aumento das atividades respiratória e subcelular, tendo como conseqüência o aumento da velocidade de germinação. Em sementes recalcitrantes de Euphoria longan, a dormência parcial também foi superada após o armazenamento sob condição úmida, por curto período de tempo (Xia et al., 1992).

Apesar do aumento no índice de velocidade de emergência das plântulas de camu-camu, o tempo médio de emergência não foi inferior a 30 dias (Tabela 2). Os efeitos de interação, encontrados entre os fatores grau de umidade e período de armazenamento nas variáveis IVE e TME (Tabela 3), reafirmaram os resultados obtidos para os fatores isolados. Assim, é possível que essa característica esteja relacionada à ecologia da espécie, cujas sementes são dispersas através de cursos d'água e de espécies da ictiofauna no período da cheia dos rios amazônicos (Mera, 1987), quando o ambiente está temporariamente inadequado ao estabele- cimento das plântulas.

\section{CONCLUSÃO}

As sementes de camu-camu devem ser armazenadas com grau de umidade elevado (próximo a 46\%) e, preferencialmente, sob temperatura de $20^{\circ} \mathrm{C}$, para manter a viabilidade e o vigor pelo período de cinco meses.

\section{REFERÊNCIAS BIBLIOGRÁFICAS}

ANDRADE, A.C.S.; CUNHA, R. Grau crítico de umidade? Informativo do Comitê Técnico de Sementes Recalcitrantes, Brasília, n.1, p.2-3, 1996.

BRASIL. Ministério da Agricultura e ReformaAgrária. Regras para análise de sementes. Brasília: CLAV/DNDV/SNAD/MA, 1992.365p.

CHIN, H.F. Recalcitrant seeds: a status report. Rome: IBPGR, 1988. 18p.

EDWARDS, T.I. Relations of germinating soy beans to temperature and length of incubations time. Plant Physiology, Washington, v.9, n.1, p.1-30, 1934.

ENCISO, R.; VILLACHICA, H. Produccion y manejo de plantas injertadas de camu camu (Myrciaria dubia) em vivero. Lima: INIA, 1993. 20p. (Informe técnico, 25).

FARRANT, J.M; PAMMENTER, N.W.; BERJAK, P. Recalcitrance - a current assessment. Seed Science and Technology, Zurich, v.16, p.155$166,1988$.

FARRANT, J.M; PAMMENTER, N.W.; BERJAK, P. Germination-associated events and the desiccation sensitivity of recalcitrant seeds - a study on three unrelated species. Planta, Berlim, v.178, n.2, p.189-198, 1989.

FERREIRA, S.A.N.; GENTIL, D.F.O. Propagação assexuada do camu-camu (Myrciaria dubia) através de enxertias do tipo garfagem. Acta Amazonica, Manaus, v.27, n.3, p.163-168, 1997.

GENTIL, D.F.O.; FERREIRA, S.A.N. Tolerância à dessecação e viabilidade de sementes de camu-camu. Revista Brasileira de Fruticultura, Jaboticabal, v.22, n.2, p.264-267, 2000.

HONG, T.D.; ELLIS, R.H. Optimum air-dry seed storage environments for arabica coffee. Seed Science and Technology, Zurich, v.20, p.547-560, 1992.

KING, M.W.; ROBERTS, E.H. The storage of recalcitrant seeds: achievements and possible approaches. Rome: IBPGR, 1979. 96p.

MAGUIRE, J.D. Speed of germination: aid in selection and evaluation for seedling emergence and vigour. Crop Science, Madison, v.2, n.2, p.176-177, 1962.

MERA, P.A.S. Camu-camu (Myrciaria dubia (H.B.K.) McVaugh). In: PRANCE, G.T. Botânica econômica de algumas espécies amazônicas. Manaus: INPA/FUA, 1987. s.p.

ROBERTS, E.H. Predicting the storage life of seeds. Seed Science and Technology, Zurich, v.1, p.499-514, 1973.

ROCA, N.A. Estudio químico-bromatológico de la Myrciaria paraensis Berg, 1965. 51f. Tesis (Grado) Facultad de Química, Universidad Nacional Mayor de San Marcos, Lima, 1965.

SILVA, C.T.C.; ANDRADE, J.S. Postharvest modifications in camu-camu fruit (Myrciaria dubia McVaugh) in response to stage of maturation and modified atmosphere. Acta Horticulturae, Wageningen, v.452, p.23-26. 1997.

XIA, Q.H.; CHEN, R.Z.; FU, J.R. Moist storage of lychee (Litchi chinensis Sonn.) and longan (Euphoria longan Steud.) seeds. Seed Science and Technology, Zurich, v.20, n.2, p.269-279, 1992. 